\title{
SENTENÇAS INTERROGATIVAS TOTAIS NEUTRAS E NÃO-NEUTRAS NO FALAR FLORIANOPOLITANO
}

\author{
MELODIC CONTOURS IN NEUTRAL AND EXPRESSIVE YES/NO QUESTIONS \\ PRODUCED BY FLORIANOPOLITANO SPEAKERS
}

\author{
Vanessa Gonzaga Nunes \\ Professora da Universidade Federal de Sergipe \\ vanessagnunes@yahoo.com.br.
}

Eva Christina Orzechowski Dias Doutoranda do Programa de Pós-Graduação em Linguística da Universidade Federal de Santa Catarina ${ }^{1}$ evaorz@gmail.com.

RESUMO: Este artigo trata de enunciados interrogativos totais (resposta sim/não) neutros e não-neutros produzidos por falantes naturais de Florianópolis. As interrogativas totais neutras são aquelas em que falante desconhece a resposta do emissor, já as não-neutras oscilam no eixo das emoções. Os parâmetros analisados foram a duração e a frequência fundamental (F0) das vogais tônicas das regiões prénuclear e nuclear das sentenças. Os dados aqui apresentados totalizam 162 produções de dois informantes, sendo um homem e uma mulher com idades de 30 e 45 anos. $\mathrm{O}$ corpus utilizado trata-se de sentenças extraídas de três textos interpretados pelos informantes segundo seus contextos semântico-pragmáticos. Em relação à duração, pudemos apurar que a taxa de elocução dos florianopolitanos analisados apresenta em media 8,5 sílabas por segundo, o que representa uma velocidade de fala superior à apresentada pela literatura. No que diz respeito à $\mathrm{F} 0$, tanto pré-núcleo quanto núcleo parecem trazer pistas de distinção entre neutras e não-neutras, com destaque para o comportamento entre movimento intrassilábico de F0 das vogais tônicas da região nuclear. Observa-se que, a partir do ponto medial da vogal tônica desta região, há um movimento de descida para as neutras e um movimento de subida para não-neutras. Os testes estatísticos demonstraram que tais diferenças são significativamente relevantes.

PALAVRAS-CHAVE: Entoação. Interrogativas totais neutras e não-neutras. Falar florianopolitano.

ABSTRACT: This study analises neutral and non-neutral yes/no questions as produced by speakers from Florianópolis (Santa Catarina/Brasil). Neutral yes/no questions are the type of questions whose answer is unknown, whereas non-neutral ones can vary along a continuum of emotional involvement. The acoustic parameters analyzed were

\footnotetext{
${ }^{1}$ Estagiária da Universitat de Barcelona através de bolsa sanduíche da CAPES - Processo $\mathrm{n}^{\circ}$ BEX 10042/13-0.
} 
duration and FO (in semitones) of stressed vowels of the pre-nuclear and nuclear regions of the sentences. Speech rate is also considered in the analysis. The data consists in 162 sentences produced by two informants, male and female, 30 and 45 years old respectively. The participants produced the utterances responding to appropriate semantic-pragmatic contexts. Our results showed that the speakers from Florianópolis spoke at an average of 8.5 syllables per second, which represents a speech rate higher than other dialects from Brazil. We also found an effect in the intrasyllabic pitch movement of neutral and non-neutral questions. For neutral and nonneutral sentences there are, respectively, upwards and downward movement, from the medial point of the stressed vowel at the nuclear region. Statistical analysis showed that these differences are relevant and significant.

KEYWORDS: Intonation. Yes/no questions. Florianópolis (Brazil) speech.

\section{INTRODUÇÃO}

O presente artigo trata da entoação de sentenças interrogativas totais neutras e não-neutras, produzidas por falantes naturais da cidade de Florianópolis, capital do estado de Santa Catarina.

É comum ouvirmos coloquialmente que o manezinho ${ }^{2}$ fala rápido, come as palavras, e apresenta um sotaque "chiado". No nível do segmento, essas marcas peculiares e pontuais podem ser explicadas em virtude, por exemplo, da produção de [J] ou [3], em posição de coda, ou, ainda, pela palatização da oclusiva alveolar em contextos não esperados, como diante de [u], fenômenos já descritos em Pagotto (2004). Mas, o que ocorre no nível do suprassegmento que dá essa impressão de rapidez?

Diante desta intuição clássica de que o florianopolitano fala rápido e que apaga os segmentos, propomos-nos a analisar o comportamento das interrogativas totais neutras e não-neutras, no que concerne à frequência fundamental e à duração, parâmetros que se influenciam mutuamente ao longo da curva entonacional e, consequentemente, revelam características dialetais perceptualmente relevantes. Para isso, será observada a taxa de elocução dos informantes para o grupo de sentenças neutras e não-neutras e essa velocidade de fala será calculada em sílabas por segundo, visando comparar com a literatura da área. As perguntas que norteiam este trabalho são:

a) No que concerne a duração relativa das vogais tônicas das regiões pré-nuclear e nuclear, há diferenças significativas entre as sentenças interrogativas consideradas neutras e não-neutras?

b) A taxa de elocução encontrada para os informantes de Florianópolis aponta para uma velocidade de fala mais rápida do que a descrita pela literatura para outras localidades, corroborando com a impressão de que o manezinho fala mais rápido do que falantes de outras regiões?

\footnotetext{
${ }^{2}$ Manezinho é um termo usado popularmente para referir-se ao povo e dialeto florianopolitano.
} 
c) O comportamento geral da curva de $\mathrm{F} 0$ de interrogativas neutras e não-neutras no falar florianopolitano corresponde ao descrito pela literatura?

d) Considerando as semelhanças entre alguns tipos de curvas de interrogativas totais já descritas pela literatura, o movimento de F0 intrassilábico das vogais tônicas, nas regiões pré-nuclear e nuclear, apresenta pistas de distinção entre sentenças neutras e não neutras nesta variedade linguística?

Para dar conta de nossa proposta e das respostas às questões levantadas, na Seção 2 será apresentada a fundamentação teórica que embasará as comparações a serem verificadas; na Seção 3, será descrita a metodologia empregada na coleta e análise dos dados. A Seção 4 apresenta os resultados, primeiramente relacionados à F0 e, em seguida, à duração. Ao final, respondemos as questões propostas.

\section{FUNDAMENTAÇÃO TEÓRICA}

\subsection{Interrogativas totais neutras}

Entende-se por uma interrogativa total neutra aquela que aceita resposta sim/não e é enunciada por um falante que desconhece a resposta do emissor. Mas nem sempre é fácil identificá-la com precisão devido às possíveis variações entonacionais. Alguns autores defendem que as interrogativas deslizam em um eixo de motivação em direção à resposta esperada (FÓNAGY, 1993; PRÉVOT, 2004). Assim, as interrogativas totais, pela carência de pistas de valor semântico-pragmático tendem a ser menos motivadas do que as interrogativas de dúvida, incerteza ou confirmação e, por isso, são consideradas perguntas mais verdadeiras ou sinceras.

Segundo Moraes (2008), a curva melódica padrão da interrogativa total neutra se caracteriza por (i) um movimento ascendente na sua primeira sílaba tônica, subida esta que pode chegar até a sílaba pós-tônica, (ii), na sequência, tem-se uma queda contínua até a sílaba pré-tônica final, que se encontra em um nível baixo, e, (iii) o final da curva se caracteriza por uma subida na sílaba tônica final, que cai eventualmente nas sílabas pós-tônicas, configurando um movimento circunflexo na região final da sentença. As notações sugeridas pelo autor são $/ \mathrm{L}+\mathrm{H}^{*} / \mathrm{e} / \mathrm{L}+<\mathrm{H}^{*} \mathrm{~L} \% /$ para as regiões pré-nuclear e nuclear, respectivamente.

Silva (2011) e Cunha et al. (2012) descreveram e compararam dialetos de capitais brasileiras. Para Florianópolis, as autoras encontraram, para regiões finais da curva de F0, um padrão circunflexo e outro ascendente, conforme ilustrado na Figura 1. 

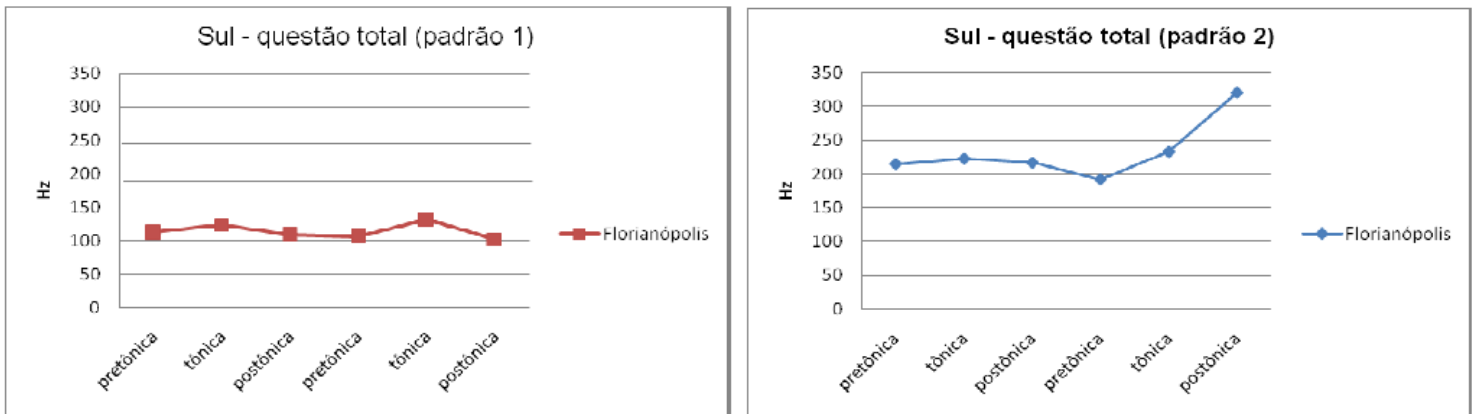

Figura 1: Padrões 1 e 2 de interrogativas totais encontrados para Florianópolis (adaptado de SILVA, 2011).

No que diz respeito a interrogativas totais neutras, Nunes (2013) encontrou para florianopolitanos o padrão circunflexo em região nuclear. Entretanto, as curvas melódicas das sentenças parecem não se completar por falta de material fonético, o que constitui um fenômeno de truncamento. Pode-se observar na Figura 2 que a curva de F0 da palavra final "Renato" não se realiza até o final e, por consequência, não se tem uma descida completa. Esse fenômeno de truncamento já foi descrito por outros autores, como Quilis (1988), Toledo e Gurlekian (2009), Silva (2011) e Dias e Alves (2013), analisando dados de diferentes variedades linguísticas.

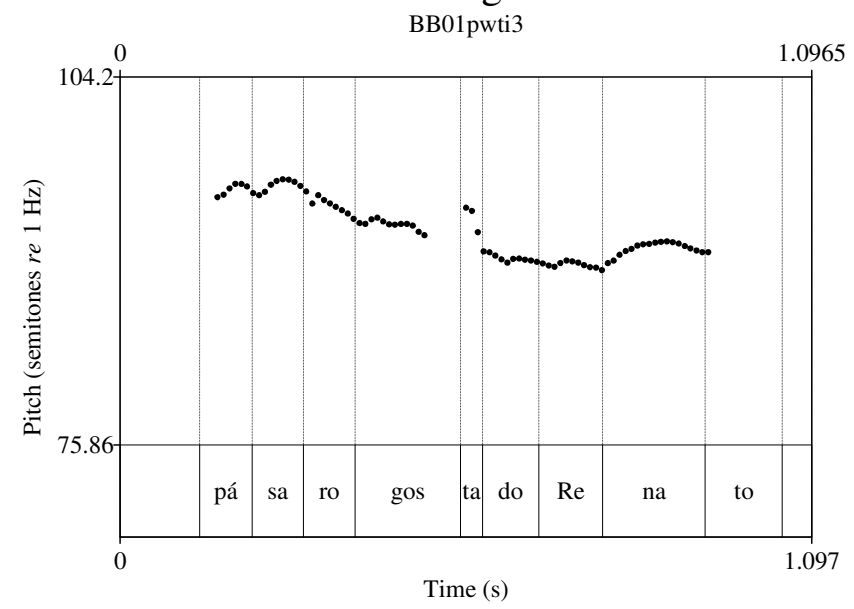

Figura 2: Curva melódica da sentença “O pássaro gosta do Renato?”, interrogativa total neutra produzida por um falante florianopolitano. Fonte: Nunes (2013).

\subsection{Interrogativas totais não-neutras}

Os contornos melódicos sofrem influência de fatores pragmáticos que variam de acordo com o contexto conversacional. Algumas das interrogativas totais que aceitam resposta sim/não podem pretender apenas confirmar algo que já é conhecido ou duvidar de uma proposição anterior. Elementos anafóricos mal elaborados, por exemplo, tendem a estimular perguntas que confirmem o que foi dito e contextos irônicos estimulam sentenças de dúvida ou de incredulidade. As perguntas retóricas pretendem criar um efeito enfático e não visam uma resposta de fato. Perguntas como Será verdade que Deus existe? e Ela não é uma fofura? não esperam respostas e têm valor semântico equivalente a uma afirmação (SADOCK, 1974 apud HAN, 2002). 
Para o português brasileiro, alguns autores trataram de classificar diversas curvas atitudinais a partir de notações distintas de acordo com os tipos de interrogativas, entre os quais destacamos Moraes \& Stein (2006), Moraes (2008), Moraes \& Colamarco (2007), e Oliveira (2011). Em Moraes (2008), encontramos que a curva de incredulidade, em relação à curva da interrogativa total neutra, se caracteriza por: (i) subida na sílaba pré-tônica final, (ii) subida tardia que se inicia na segunda metade da vogal da sílaba tônica, (iii) nível baixo na sílaba tônica final e (iv) alongamento da sílaba tônica final. Essa curva de F0 apresenta dois alvos melódicos na sílaba tônica, um L na primeira metade da vogal, e um $H$ na segunda metade, de modo que a notação sugerida é: $/ \mathrm{H}+[\mathrm{LH}] * \mathrm{~L} \% /$.

As interrogativas de confirmação descritas em Moraes \& Stein (2006) e Moraes (2008) apresentaram uma subida na curva de F0 na primeira sílaba tônica, movimento que se prolonga ao longo do enunciado, incluindo a sílaba pré-tônica, e que cai, posteriormente, sobre a sílaba tônica final. O movimento intrassilábico deste tipo de curva apresenta queda bastante acentuada. Para esse tipo de curva, sugere-se a notação $/ ; \mathrm{H}+\mathrm{L}^{*}>\mathrm{L} \% /$, sendo que o $\mathrm{L}$ seguido do diacrítico > representa o alinhamento à esquerda do pico de F0 na porção mediana da vogal (MORAES \& STEIN, 2006; MORAES, 2008).

Em Moraes (2008), as diferenças entre as interrogativas totais neutras e as de pedido aparecem na implementação fonética que se dá no interior da sílaba. Para o autor, tais sentenças apresentam curvas semelhantes no pré-núcleo e, para o núcleo, movimento ascendente na sílaba tônica e descendente na pós-tônica. A distinção parece estar no alinhamento do pico de F0. O alinhamento nas interrogativas neutras ocorre no final da sílaba tônica, enquanto, nas sentenças de pedido, o alinhamento do pico de F0 se dá na porção inicial da sílaba tônica.

Oliveira (2011) buscou apurar semelhanças e diferenças existentes entre as curvas de dúvida, incredulidade e incerteza a partir dos parâmetros de duração e intensidade. Para isso, contou com a participação de 16 estudantes de artes cênicas, habitantes da cidade de Belo Horizonte que leram e emitiram enunciados a partir de etapas elaboradas pela pesquisadora. Dentre os resultados encontrados, destacamos que as sentenças de dúvida apresentaram, em relação à incredulidade e incerteza, F0 mais elevada no começo da sentença e mais baixa no final. Essa modalidade apresentou ainda vogais tônicas e prétônicas com menor duração. As curvas de incerteza apresentaram maior duração da vogal tônica (OLIVEIRA, 2011).

No estudo de Silva (2008), comparando curvas atitudinais de incerteza e dúvida frente a curvas de certeza, foi verificado que a variação da altura ${ }^{3}$ e os valores médios de F0 são maiores nas curvas atitudinais de dúvida e incerteza. Em estudos sobre outras línguas, a variação da altura de F0 também se mostra como um fator influente para diferenciar as diversas curvas atitudinais (LADD, 1996; PRIETO, 2003).

\footnotetext{
${ }^{3}$ Utilizamos o termo variação de altura de $f 0$ para referirmos à extensão de um movimento melódico ascendente ou descendente na curva entoacional, com base em Tenani (2006). Em Ladd (2008), é encontrado o termo pitch range para referir-se a tais variações melódicas.
} 
Em relação à Florianópolis, Nunes (2013) iniciou estudos que pretendem descrever curvas de interrogativas neutras, de dúvida e incerteza na variante florianopolitana. No entanto, o teste de percepção que pretendia endossar se falantes desse dialeto identificavam tais atitudes não se mostrou consistente no que diz respeito à distinção das curvas de dúvida e incerteza. Os juízes apresentaram baixo índice de aceitação das sentenças propostas como de confirmação (36\%) e de dúvida (27\%), mas alto índice de aceitação daquelas consideradas previamente como neutras (72\%). Por isso, para este trabalho, agrupamos as diferentes curvas atitudinais, classificado-as como não-neutras, para compará-las às neutras.

Apresentaremos, portanto, uma análise de produção de sentenças classificadas como interrogativas totais neutras e interrogativas totais não-neutras, sendo que esse último grupo engloba perguntas que oscilam no eixo das emoções, podendo ser interpretadas, por exemplo, como de confirmação ou dúvida. O objetivo do estudo é verificar possíveis diferenças entre as curvas entonacionais dessas sentenças com relação aos parâmetros acústicos de duração e de frequência fundamental (F0), observados nas vogais tônicas das regiões pré-nuclear e nuclear.

\subsection{Sobre a taxa de elocução}

Pesquisas sobre sentenças atitudinais têm mostrado que a frequência e a velocidade de fala são parâmetros que oscilam de acordo com a emoção em questão. Segundo Scherer (2003), sentimentos de tristeza e tédio apresentam diminuição nos valores de F0 e segmentos de maior duração e consequentemente taxa de elocução mais lenta.

Entretanto, a velocidade de fala está atrelada também ao dialeto, gênero, estilo de fala, etc. (LAVER, 1994). A maioria dos autores que pesquisa velocidade de fala regional opta por calcular a taxa de elocução através da relação número de sílabas por segundo ou minuto ou número de palavras por minuto. Meirelles \& Gambarini (2011) trabalharam com palavras específicas encaixadas dentro de frases-veículo e encontraram para mineiros e paulistas 7,5 e 6,4 sílabas por segundo, respectivamente. Oliveira (2011), que analisou a variante de Belo Horizonte, encontrou para interrogativas de dúvida, incredulidade e incerteza valores em torno de 6,12, 5,46 e 4,5 sílabas por segundo, respectivamente (OLIVEIRA, 2011).

No que concerne à cidade de Florianópolis, as pesquisas de Nunes $(2010,2011)$, realizadas através da metodologia $\mathrm{AMPER}^{4}$, apontam para velocidades de fala relativamente altas para esse dialeto em comparação com o falar de Lages (cidade na região oeste de Santa Catarina). Além disso, a autora encontrou alta incidência de apagamentos tanto em declarativas quanto em interrogativas, que poderiam estar influenciando na taxa de elocução desses falantes. Dias e Seara (2013) realizaram um estudo com crianças e adultos naturais de Florianópolis que leram palavras encaixadas em frases-veículo. As pesquisadoras encontraram as taxas de elocução de 5,2 e 6,4 sílabas por segundo para crianças e adultos, respectivamente.

\footnotetext{
${ }^{4}$ Metodologia empregada na construção de um Atlas Multimídia Prosódico do Espaço Românico AMPER (para maiores informações, consulte o endereço: http://pfonetica.web.ua.pt/AMPER-POR.htm)
} 


\section{METODOLOGIA}

\subsection{Seleção das frases para análise}

Parte das sentenças aqui analisadas foram usadas em um teste perceptual de identificação de sentenças neutras e não-neutras, realizado em Nunes, (2013), que contou com dez juízes florianopolitanos e dez de outras localidades. Os participantes ouviram estímulos correspondentes a sentenças interrogativas totais produzidas por falantes florianopolitanos e julgaram se elas eram neutras ou não-neutras. A partir dos resultados desse teste, foi possível formar um grupo de sentenças classificadas como neutras e outro grupo classificadas como não-neutras.

\subsection{Coleta de dados}

O experimento de produção foi realizado com dois participantes adultos naturais de Florianópolis, sendo um do sexo feminino e outro do sexo masculino, com 30 e 45 anos, respectivamente. Visando a comparação das sentenças, o corpus foi elaborado seguindo o modelo AMPER, pois contemplou seja para região pré-nuclear, seja para nuclear, todas as combinações acentuais possíveis (oxítonas, paroxítonas e proparoxítonas), conforme mostram os exemplos abaixo:

a) A $\underbrace{\text { Nazaré ligou para o Renato? }}_{\text {oxítona }} \underbrace{\text { Rat }}_{\text {paroxítona }}$

b) A Carina levou o jacaré?

paroxítona oxítona

c) A Pâmela partiu na dureza?

proparoxítona paroxítona

Os informantes receberam com antecedência os textos que iriam produzir e puderam se preparar para a gravação, encontrando as interpretações que julgavam mais adequadas ao diálogo. Ao total, os dois informantes produziram 162 sentenças interrogativas totais, sendo 54 neutras e 108 não-neutras.

As gravações foram realizadas em uma cabine com isolamento acústico, com uma placa de áudio MOTU Ultralite mk3 Hybrid conectada a um computador iMac, a um microfone Shure (modelo SM48) e a um fone de ouvido Behringer (modelo HPX2000). Utilizaram-se ainda os softwares Praat (versão 5.3.59 para Mac OS X), Ocenaudio (Versão 2 rc1) e CueMix FX (versão 1.657985$)$ para auxílio nas gravações.

Depois de realizada a gravação, extraímos as sentenças do texto completo, que foram segmentadas e receberam rótulos que as identificassem. Em seguida, foram 
extraídos os valores de duração, intensidade e de F0, e gerados gráficos e histogramas, a partir de scripts e softwares fornecidos pela interface do Projeto AMPER ${ }^{5}$.

\subsection{Análise dos dados}

A análise foi feita com uma amostra de 162 enunciados, divididos em dois conjuntos: 54 sentenças interrogativas totais neutras e 108 sentenças interrogativas nãoneutras. Observou-se o comportamento das vogais tônicas da região pré-nuclear e nuclear, com relação aos parâmetros acústicos de duração e de frequência fundamental (F0), esta última extraída de três momentos vocálicos: inicial, medial e final.

Para poder agrupar os dados dos participantes do sexo masculino e feminino, os valores de duração das vogais foram relativizados (com respeito à duração dos enunciados que as continham) e os valores de frequência fundamental foram transformados em semitons. Podem-se obter medidas de F0 em semitons a partir da distância entre duas frequências, conforme sugerido em Nooteboom (1997) e MartínezCeldrán (2007):

$$
D=12 / \log _{10} 2 * \log _{10}\left(f_{1} / f_{2}\right)
$$

Considerou-se, para a fórmula $D$, que o valor de referência corresponde ao valor médio das frequências extraídas de cada sentença, de modo que se obtiveram as distâncias entre as frequências alvos $(\mathrm{F} 1)$ e as frequências médias (F2) das sentenças correspondentes. No estudo de Rietveld \& Gussenhoven (1985), observou-se que uma diferença de 1,5 semitons pode ser suficiente para que se percebam proeminências de F0.

A duração relativa das vogais foi calculada com base na duração dos enunciados em que eram realizadas, de modo que se obteve um percentual de ocupação da vogal dentro dos enunciados, evitando-se, portanto, diferenças relacionadas à influência da velocidade de fala (taxa de elocução) dos participantes.

Após obter os valores de duração relativa e os valores de F0 em semitons, foram feitas rodadas estatísticas, utilizando-se o programa SPSS 6 . O teste não-paramétrico de Mann-Whitney $U$ foi utilizado para comparar os valores acústicos entre os grupos de sentenças. Foi considerado um intervalo de confiança de 95\%, conforme convencionado em pesquisas sociais (BARBETTA, 2011; MARTINS, 2011).

\section{RESULTADOS}

Nesta pesquisa, investigamos possíveis diferenças de frequência fundamental e duração entre sentenças interrogativas neutras e não-neutras em dados de falantes da variedade de Florianópolis. Esses parâmetros acústicos foram observados nas vogais

\footnotetext{
${ }^{5}$ Para gerar os gráficos apresentados neste trabalho, utilizou-se o Programa Amper-2006 (BOBO et al., 2007).

${ }^{6}$ SPSS Statistic 20.0. Polar Engineering and Consulting, copyright 1993-2014.
} 
tônicas da região pré-nuclear e nuclear em um conjunto de 54 sentenças consideradas neutras e 108 consideradas não-neutras.

\subsection{Sobre a frequência fundamental de neutras e não neutras}

Com relação à $\mathrm{F} 0$, encontramos certas características que podem constituir pistas para a diferenciação das interrogativas totais neutras e não-neutras. As Figuras 3, 4 e 5 ilustram exemplos de curvas de F0 de interrogativas totais neutras e não-neutras, com palavras oxítonas, paroxítonas e proparoxítonas em região pré-nuclear e nuclear.

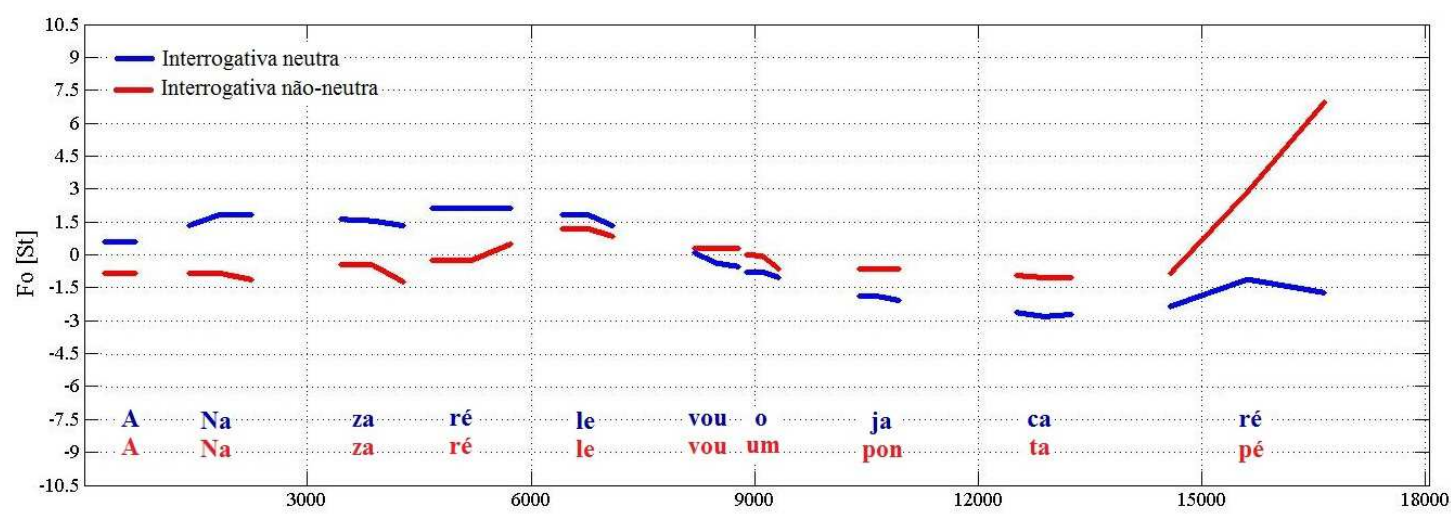

Figura 3: Curvas geradas a partir dos valores de F0 (semitons), extraídos das regiões inicial, medial e final, da sentença interrogativa total neutra A Nazaré levou o jacaré? e da não-neutra A Nazaré levou um pontapé?, produzidas por uma informante do sexo feminino.

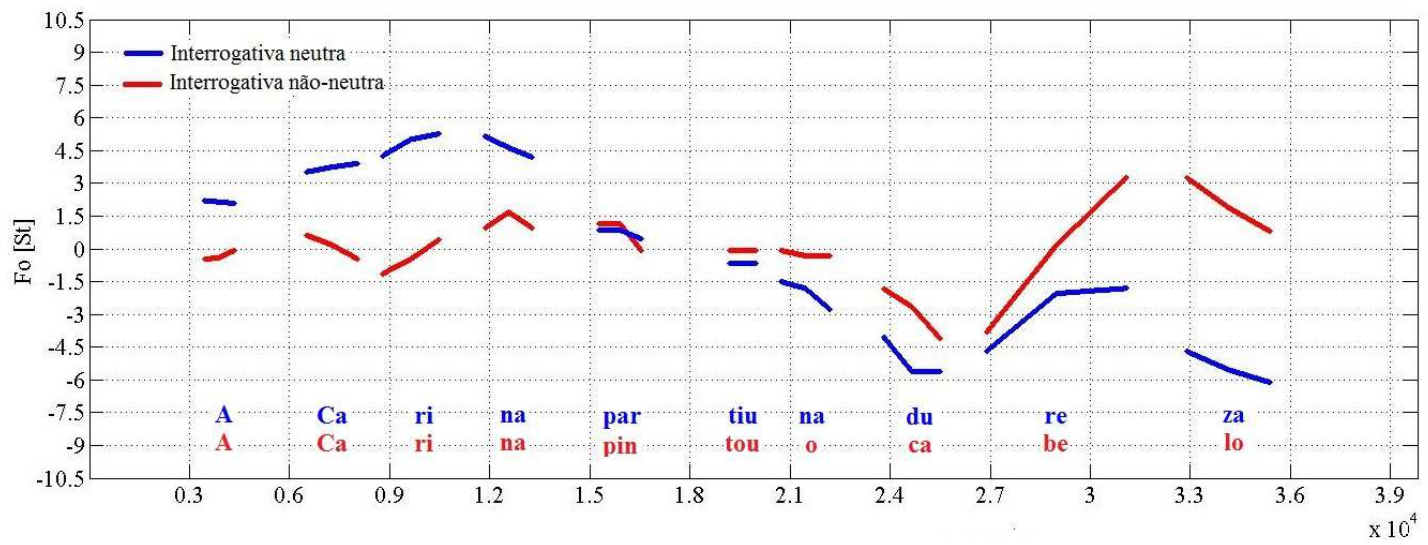

Figura 4: Curvas geradas a partir dos valores de F0 (semitons), extraídos das regiões inicial, medial e final, da sentença interrogativa total neutra A Carina partiu na dureza? e da não-neutra A Carina pintou o cabelo?, produzidas por uma informante do sexo feminino. 


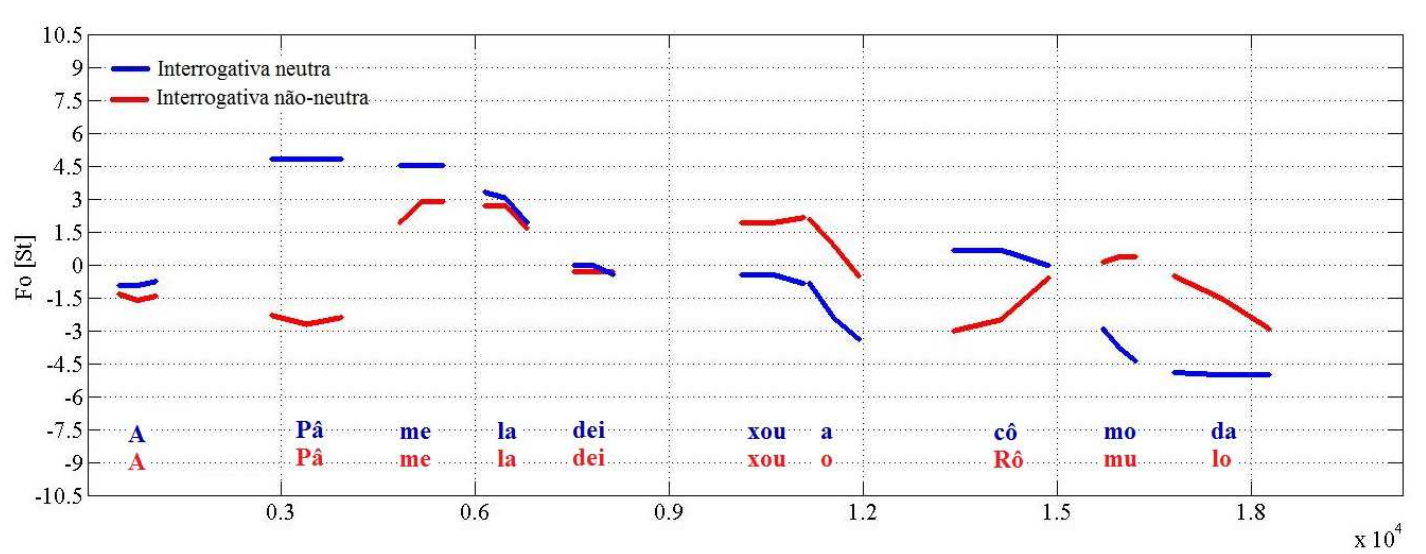

Figura 5: Curvas geradas a partir dos valores de F0 (semitons), extraídos das regiões inicial, medial e final, da sentença interrogativa total neutra $A$ Pâmela deixou a cômoda? e da não-neutra A Pâmela deixou o Rômulo?, produzidas por uma informante do sexo feminino.

Como podemos observar pelas Figuras 3, 4 e 5, embora as configurações sejam distintas, as curvas apresentam predominantemente movimento circunflexo em região nuclear, independentemente de serem neutras ou não-neutras. Nas sentenças oxítonas (Figura 3), entretanto, o movimento circunflexo não é evidente como nos demais casos (Figuras 4 e 5), uma vez que essas sentenças não terminam com sílabas pós-tônicas, o que impede que o movimento de descida de F0 se realize, caracterizando, dessa forma, o fenômeno de truncamento.

Verificamos ainda que, em geral, as sentenças neutras, representadas pelas curvas azuis, apresentam frequências mais altas na região pré-nuclear (início das sentenças) do que as não-neutras, representadas pelas curvas vermelhas, configuração que se mantém ao longo de toda a região pré-nuclear. Já na região nuclear (final das sentenças), as sentenças não-neutras mostraram valores de F0 mais elevados, o que se vê ilustrado pela maior altura das curvas em vermelho nas Figuras 3, 4 e 5.

As diferenças entre as curvas dos dois grupos podem ser observadas também quantitativamente, conforme os dados apresentados na Tabela 1. Observa-se que os valores de F0 são sempre mais elevados nas sentenças neutras para os três pontos das vogais tônicas da região pré-nuclear (inicial, medial e final), sendo estatisticamente significativa a diferença entre o primeiro ponto das vogais das sentenças neutras e seu correspondente das sentenças não neutras. 
Tabela 1: Comparação dos valores médios e desvios padrões (parênteses) de F0 (semitons) das vogais tônicas nas regiões pré-nuclear e nuclear das sentenças interrogativas consideradas neutras e não-neutras.

\begin{tabular}{cccccc}
\hline \multicolumn{1}{c}{ Ro } & Região da sentença & Região da vogal & Neutras & Não-neutras & Significância \\
\hline $\begin{array}{c}\text { Valores em } \\
\text { Semitons (St) }\end{array}$ & Pré-núcleo & Inicial & $2,39(1,86)$ & $1,41(1,87)$ & $\chi^{2}=-\mathbf{3 , 2 2 ,} \mathbf{p = , 0 0 1}$ \\
& & Medial & $3,04(1,94)$ & $2,58(1,94)$ & $\chi^{2}=-1,48, \mathrm{p}=, 138$ \\
& & Final & $3,39(2,01)$ & $3,21(1,87)$ & $\chi^{2}=-, 723, \mathrm{p}=, 470$ \\
\cline { 2 - 6 } & Núcleo & Inicial &,$- 98(1,67)$ & $-0,81(2,05)$ & $\chi^{2}=, 70, \mathrm{p}=, 483$ \\
& & Medial & $1,22(1,59)$ & $1,14(2,64)$ & $\chi^{2}=-, 33, \mathrm{p}=, 742$ \\
& & Final &, $87(2,36)$ & $1,61(2,68)$ & $\chi^{2}=1,75, \mathrm{p}=, 080$ \\
\hline Número de dados & & & 54 & 108 & \\
\hline
\end{tabular}

\subsubsection{Com foco na região pré-nuclear}

Olhando o detalhe do suprassegmento na região pré-nuclear, vê-se que o comportamento intrassilábico de F0 das vogais tônicas das sentenças neutras e nãoneutras são distintos. Conforme os dados apresentados na Tabela 2, as diferenças de F0, medidas entre os pontos inicial e medial e entre os pontos medial e final, são significativamente maiores para as sentenças não-neutras.

Tabela 2: Diferenças de valores de F0 (semitons) entre os pontos inicial, medial e final das vogais tônicas na região pré-nuclear das sentenças interrogativas consideradas neutras e não-neutras.

\begin{tabular}{|c|c|c|c|c|c|}
\hline Fo & Região da sentença & $\begin{array}{l}\text { Região da vogal } \\
\text { (entre pontos) }\end{array}$ & Neutras & Não-neutras & Significância \\
\hline \multirow{2}{*}{$\begin{array}{c}\text { Valores em } \\
\text { Semitons (St) }\end{array}$} & \multirow[t]{2}{*}{ Pré-núcleo } & Inicial e medial & $0,65(1,20)$ & $1,06(1,13)$ & $\chi^{2}=2,87, p=, 004$ \\
\hline & & Medial e final & $0,35(0,64)$ & $0,64(0,80)$ & $\chi^{2}=2,031, p=, 042$ \\
\hline \multicolumn{3}{|c|}{ Número de dados } & 54 & 108 & \\
\hline
\end{tabular}

Outro ponto a ser observado na região pré-nuclear concerne ao movimento de F0 entre a vogal tônica e a pós-tônica da região pré-nuclear que se configura de maneira distinta para cada grupo (ver Figuras 3, 4 e 5). Há um movimento ascendentedescendente entre as tônicas e pós-tônicas das sentenças neutras, já nas não-neutras, o movimento ascendente das tônicas continua nas pós-tônicas, o que pode ser uma pista de discriminação entre elas.

\subsubsection{Com foco na região nuclear}

O movimento intrassilábico de F0 das vogais tônicas da região nuclear se configura de maneira distinta para os diferentes grupos. Observa-se que, a partir do ponto medial da vogal, há um movimento de descida para as neutras e um movimento de subida para não-neutras. Ao comparar quantitativamente esses valores, conforme mostrado na Tabela 3, verificamos que essas diferenças são estatisticamente relevantes: para as sentenças neutras, o movimento entre os pontos medial e final é negativo, ou seja, descendente $(-0,35 \mathrm{st})$, e para as sentenças não-neutras, o movimento é positivo, ou seja, ascendente $(0,49 \mathrm{st})$. 
Tabela 3: Diferenças de valores de F0 (semitons) entre os pontos inicial, medial e final das vogais tônicas na região nuclear das sentenças interrogativas consideradas neutras e não-neutras.

\begin{tabular}{|c|c|c|c|c|c|}
\hline F0 & Região da sentença & $\begin{array}{l}\text { Região da vogal } \\
\text { (entre pontos) }\end{array}$ & Neutras & Não-neutras & Significância \\
\hline \multirow{2}{*}{$\begin{array}{c}\text { Valores em } \\
\text { Semitons (St) }\end{array}$} & \multirow[t]{2}{*}{ Núcleo } & Inicial e medial & $2,20(1,82)$ & $1,90(2,13)$ & $\chi^{2}=-1,12, p=, 264$ \\
\hline & & Medial e final & $-0,35(1,66)$ & $0,49(2,13)$ & $\chi^{2}=3,28, p=, 001$ \\
\hline \multicolumn{3}{|c|}{ Número de dados } & 54 & 108 & \\
\hline
\end{tabular}

\subsection{Sobre a duração de neutras e não-neutras}

Com relação à duração relativa, apuramos que as vogais tônicas da região nuclear apresentam duração com valores de aproximadamente o dobro dos valores referentes às vogais tônicas da região pré-nuclear, tanto para as sentenças neutras, quanto para as não-neutras, conforme mostra a Tabela 4.

Tabela 4: Comparação dos valores médios e desvios padrões (parênteses) da duração relativa (\%) das vogais tônicas nas regiões pré-nuclear e nuclear e da taxa de elocução das interrogativas neutras e nãoneutras.

\begin{tabular}{llccc}
\hline Duração & Região da sentença & Neutras & Não-neutras & Significância \\
\hline Valores relativos $(\%)$ & Pré-núcleo & $5,68(1,09)$ & $5,82(1,53)$ & $\chi^{2}=, 572, p=, 567$ \\
& Núcleo & $10,76(3,91)$ & $11,04(3,49)$ & $\chi^{2}=, 67, \mathrm{p}=, 505$ \\
\hline Taxa de elocução $($ síl/seg) & & 8,61 & 8,41 & $\chi^{2}=-, 38, \mathrm{p}=, 704$ \\
\hline Número de dados & & 54 & 108 & \\
\hline
\end{tabular}

Ao comparar os grupos de sentenças neutras e não-neutras, observamos que a duração das vogais tônicas não se mostrou significativa para distinguir esses grupos de sentenças, conforme revela os resultados do teste de Mann-Whitney (Tabela 4).

Os resultados referentes à taxa de elocução, calculada a partir da quantidade de sílabas por segundo, mostraram que as sentenças interrogativas totais neutras e as nãoneutras foram produzidas com velocidades aproximadas de 8,61 e 8,41 sílabas por segundo, respectivamente.

\section{CONSIDERAÇÕES FINAIS}

Este trabalho teve o intuito de contribuir para a descrição da prosódia do falar florianopolitano. Observamos sentenças interrogativas totais neutras e não-neutras em dados de dois falantes adultos naturais de Florianópolis, objetivando realizar uma descrição do comportamento das regiões pré-nuclear e nuclear dessas sentenças, no que diz respeito à $\mathrm{F} 0$ e duração. Retomando nossas perguntas de pesquisa, destacamos, a seguir, os resultados que se mostraram relevantes ao longo das análises. 
a) No que concerne à duração relativa das vogais tônicas das regiões pré-nuclear e nuclear, há diferenças significativas entre as sentenças interrogativas consideradas neutras e não-neutras?

Apesar de pesquisas como a de Celeste (2010) e Oliveira (2011) terem observado diferenças de taxa de elocução com relação a algumas sentenças atitudinais, neste estudo, com dados de falantes florianopolitanos, não foram encontradas diferenças significativas de duração entre sentenças interrogativas neutras e não-neutras. Mas, apuramos que houve diferença relevantivamente alta entre as regiões pré-nucleares e nuclerares de cada grupo de sentenças. As vogais tônicas da região nuclear apresentam duração com valores de aproximadamente o dobro dos valores referentes às vogais tônicas da região pré-nuclear, tanto para as sentenças neutras, como para não-neutras. Essa diferença parece relacionada com as diferenças de F0 em semitons observadas entre o pré-núcleo e o núcleo das sentenças neutras e não-neutras, uma vez que essas diferenças de F0 também foram maiores na região nuclear para ambos os grupos de sentenças. Futuros testes de correlação podem ou não comprovar essa hipótese.

b) A taxa de elocução encontrada para os informantes de Florianópolis aponta para uma velocidade de fala mais rápida do que a descrita pela literatura para outras localidades, corroborando com a impressão de que o manezinho fala mais rápido que falantes de outras regiões?

Apuramos, para os florianopolitanos, valores de taxa de elocução de 8,61 e 8,41 sílabas por segundo para interrogativas totais neutras e não-neutras, respectivamente. Observa-se que esses valores são superiores aos encontrados na literatura (MEIRELLES \& GAMBARINI, 2011; OLIVEIRA, 2011; DIAS \& SEARA, 2013). Ainda que as metodologias dos estudos tenham sido distintas, acreditamos que as taxas com valores mais altos para os nossos informantes podem ser uma forte pista sobre a impressão de que o florianopolitano fala mais rápido do que falantes de outras localidades, independentemente da modalidade ou da atitude.

c) $\mathrm{O}$ comportamento geral da curva de $\mathrm{F} 0$ de interrogativas neutras e não-neutras no falar florianopolitano corresponde ao descrito pela literatura?

Em relação às neutras, o desenho da curva tanto para a região pré-nuclear $\left(/ \mathrm{L}+\mathrm{H}^{*} /\right)$ quanto para a nuclear $\left(/ \mathrm{L}+<\mathrm{H}^{*} \mathrm{~L} \% /\right)$ corresponde com a descrição de Moraes (2008). O movimento circunflexo da região nuclear corrobora com uma das descrições apresentadas por Silva (2011) e Cunha et al. (2012) para o falar de Florianópolis. As oxítonas apresentam o fenômeno truncamento, observado também em outros estudos (OLIVEIRA, 2011; SILVA, 2011; NUNES, 2011; DIAS \& ALVES, 2013).

No geral, observou-se que as vogais tônicas das sentenças neutras apresentam curvas de F0 mais altas na região pré-nuclear e predominantemente mais baixas na região nuclear, em comparação com as sentenças não-neutras. Esse resultado pode constituir-se também como uma pista para o efeito da extensão da variação tonal sobre as diferentes curvas atitudinais, que já é registrado na literatura (OLIVEIRA, 2011; SILVA, 2008). 
d) Considerando as semelhanças entre alguns tipos de curvas de interrogativas totais já descritas pela literatura, o movimento de F0 intrassilábico das vogais tônicas, nas regiões pré-nuclear e nuclear, apresenta pistas de distinção entre sentenças neutras e não neutras nesta variedade linguística?

Em relação às não-neutras, pudemos apurar que há um movimento intrassilábico de F0 ascendente a partir da segunda metade da tônica, tanto para a região pré-nuclear quanto nuclear. Os valores encontrados para as diferenças entre esses movimentos ascendentes se mostraram estatisticamente significativos, o que indica, dessa forma, um possível parâmetro para diferenciar essas curvas atitudinais. Esse comportamento já havia sido descrito por Moraes (2008) para a curva atitudinal de incredulidade.

Entendendo que o movimento intrassilábico tem se mostrado relevante em estudos sobre curvas melódicas de diferentes variedades linguísticas, sugerem-se, para estudos futuros, testes que contemplem o movimento interno à vogal tônica do núcleo, com o objetivo de encontrar as pistas, talvez sutis, de distinção atitudinais de cada dialeto. Nesse caso, será necessário estar atento ao procedimento de coleta de F0. Atualmente, a extração automática fornece valores de três pontos das vogais (início, meio e fim) que podem não ser suficientes para mensurar a extensão tonal, bem como os picos internos às silabas.

Acreditamos que outra pista que diferencia os grupos aqui em estudo pode estar entre a tônica e a pós-tônica, uma vez que, nas sentenças neutras, existe um movimento de subida e descida entre a vogal tônica e a pós-tônica e, nas não-neutras, a subida de F0 da tônica continua na pós-tônica. Esse comportamento foi encontrado predominantemente na região pré-nuclear.

Para pesquisas futuras, pretendemos lidar com as curvas atitudinais do grupo das não-neutras separadamente, mas precisaremos aumentar o corpus e realizar testes perceptuais que endossem os agrupamentos e classificações.

\section{REFERÊNCIAS}

BARBETTA, P. A.. Estatística Aplicada às Ciências Sociais. 5. ed. Florianópolis: Editora da UFSC, 2011.

BOBO, M. J. L. et al.. Análisis y representación de la entonación. Replanteamiento metodológico en el marco del proyecto AMPER. In: DORTA, J. (ed.). La prosodia en el ámbito lingüístico románico. La Página, 2007.

CELESTE, L.. A prosódia na expressão de atitudes na fala de indivíduos com e sem gagueira. $271 \mathrm{f}$. Tese (Doutorado em Linguística) - Faculdade de Letras, Universidade Federal de Minas Gerais, Belo Horizonte, 2010.

CUNHA, C. S.; SILVESTRE, A. P. S.; SILVA, J. C. B.. A prosódia das capitais brasileiras. In: ALTINO, F. C.. Múltiplos olhares sobre a diversidade linguística: uma homenagem a Vanderci de Andrade Aguilera. Londrina: Midiograf, 2012. 
DIAS, E. C. O.; ALVES, M. A.. Análise de Produção de Sentenças Interrogativas Totais em Aprendizes Brasileiros de Espanhol como Língua Estrangeira. Journal of Speech Sciences, v. 2, p. 43-63, 2013.

DIAS, E. C. O.; SEARA, I. C.. Redução e apagamento de vogais átonas finais na fala de crianças e adultos de florianópolis: uma análise acústica. Letrônica. v. 6, n. 1, p. 71-93, 2013.

FÓNAGY, I.. As funções modais da entoação. Cadernos de Estudos Linguísticos. Campinas, 1993, p. 25-65, jul/dez, 1993.

HAN, C.. Interpreting interrogatives as rhetorical questions. Lingua, [S.1.], n.112, p. 201-229, 2002.

LADD, D. R.. Intonational phonology. Cambridge: Cambridge University Press, 1996.

LAVER, J.. Principles of phonetics. Cambridge: Cambridge University Press, 1994.

MARTÍNEZ-CELDRÁN, E.. Análisis espectrográfico de los sonidos del habla. Ariel, 2007.

MARTINS, C.. Manual de análise de dados quantitativos com recurso ao IBM SPSS. Braga: Psiquilibríos Edições, 20011.

MEIRELLES, A.; GAMBARINI, V.. Tipologia rítmica de dialetos do português brasileiro. Colóquio Brasileiro de Prosódia da Fala, 3, 2011, Belo Horizonte. Anais do III Colóquio Brasileiro de Prosódia da Fala. Belo Horizonte: [s.n.], 2011, p. 4-7.

MORAES, J. A.; STEIN, C. C.. Attitudinal patterns in Brazilian Portuguese intonation: analysis and synthesis. International Conference on Speech Prosody, 3, 2006, Dresden. Proceedings of the $3^{\text {rd }}$ Speech Prosody. Dresden: [s.n.], 2006.p. 137-141.

MORAES, J. A.. The Pitch Accents in brazilian portuguese: analysis by synthesis. In: Fourth Conference on Speech Prosody, 2008, Campinas. Proceedings of the $4^{\text {th }}$ Speech Prosody. Campinas: Unicamp, 2008. p. 389-397.

MORAES, J. A.; COLAMARCO, M.. Você está pedindo ou perguntando? Uma análise entonacional de pedidos e perguntas no português do Brasil. Revista de Estudos Linguísticos, Belo Horizonte, v. 15, jul./dez., p. 113-126, 2007.

NOOTEBOOM, S.. The prosody of speech: melody and rhythm. In: HARDCASTLE, W. J.; LAVER, J. (eds.). The handbook of phonetic sciences. Cambridge: Blackwell Publishers, 1997. p. 641-673.

NUNES, V. G.. O apagamento de vogais átonas: o falar florianopolitano. In: RAUEN, F. J. (org.). Anais do IX Encontro do Círculo de Estudos Linguísticos do Sul. Palhoça: Ed. da Unisul, 2010.

NUNES, V. G.. Análises entonacionais de sentenças declarativas e interrogativas totais nos falares florianopolitano e lageano. Dissertação (Mestrado em Linguística) Universidade Federal de Santa Catarina, 2011.

NUNES, V. G.. Características entonacionais de sentenças interrogativas totais em falares catarinenses e sergipanos. Qualificação de doutorado. Universidade Federal de Santa Catarina, 2013. 
OLIVEIRA, B. F. V.. A prosódia na expressão das atitudes de dúvida, incerteza e incredulidade no português brasileiro. Dissertação (Mestrado). Universidade Federal de Minas Gerais. Belo Horizonte, 2011. 194 p.

PAGOTTO, E. G.. Variação e (é) identidade. Maceió: EDUFAL, 2004.

PRÉVOT, L.. Structures sémantiques et pragmatiques pour la modélisation de la cohérence dans des dialogues finalisés. Tese (Doutorado). Université Paul Sabatier, Toulouse III, 2004.

PRIETO, P.. Teorías lingüísticas de la entonación. In: PRIETO, P. (org.). Teorías de la entonación. Ariel, 2003.

QUILIS, A.. Estudio comparativo entre la entonación portuguesa (de Brasil) y la española. Revista de Filologia Española, [S.1.], n.68, p. 33-65, 1988.

RIETVELD, A. C. M.; GUSSENHOVEN, C.. On the relation between pitch excursion size and prommence. Journal of Phonetics, v. 13, p. 299-308, 1985.

SADOCK, J. M.. Towards a linguistic theory of speech acts. New York: Academic Press, 1974.

SCHERER, K. R.. Vocal communication of emotion: A review of research paradigms, Speech Communication 40, p. 227-256, 2003.

SILVA, J. P. G.. Análise dos aspectos prosódicos na expressão da certeza e da dúvida no português brasileiro. Dissertação (Mestrado). Universidade Federal de Minas Gerais. Belo Horizonte, 2008.

SILVA, J. C. B.. A Prosódia regional em enunciados interrogativos espontâneos do português do Brasil. Revista Gatilho, ano VII, v.13, p.1-13, set.2011.

SILVA, J. C. B.; CUNHA, C. S.. Caracterização prosódica dos falares brasileiros: a questão total em Recife, Rio de Janeiro e Florianópolis. Antares, Letras e Humanidades, [S.1.], v. 3, n.6, p. 282-294, jul./dez. 2011.

TENANI, L.. Domínios prosódicos no Português Brasileiro: evidências rítmica, entoacional e segmental. Estudos Linguísticos, v. XXXV, p. 118-131, 2006.

TOLEDO, G. A.; GURLEKIAN, Jorge.. Amper-Argentina: tonemas en oraciones interrogativas absolutas. Estudios de Fonética Experimental, Barcelona, n.18, p. 401415, 2009.

Data de submissão: 18/07/2014

Data de aceite: $25 / 04 / 2015$ 